\title{
REMOTE SENSING AND NIGHT TIME URBAN HEAT ISLAND
}

\author{
Blanca Arellano ${ }^{1} \&$ Josep Roca $^{1 *}$ \\ ${ }^{1}$ Technical University of Catalonia
}

\section{ICWG III/1: Thematic Information Extraction}

\begin{abstract}
KEY WORDS: Nighttime Urban Heat Island, LST, Emissivity, Fractional Cover, Landsat 8, summer and winter NDVI,
\end{abstract} Metropolitan Area of Barcelona

\begin{abstract}
:
The urban climate literature has highlighted the remarkable prominence of nighttime UHI phenomenon. During nighttime the UHI effects become more evident due to the greater thermal inertia of the materials used in urban fabric. It is during the night when the heat accumulated in urban materials, especially in contexts of heat waves, can generate significant health risks. The low cooling capacity of urban construction materials negatively affects the comfort and the health of urban dwellers. However, and despite the great importance of night stress due to heat, the study of night UHIs is still underdeveloped. In this context, this paper aims to determine nighttime LST contrasting Landsat's very limited nighttime images with daytime ones. The example developed refers to heat wave situations during the summer 2015. The case study is the Metropolitan Area of Barcelona (35 municipalities, $636 \mathrm{~km}^{2}, 3.3$ million inhabitants).
\end{abstract}

\section{INTRODUCTION}

Although the climate of the cities depends fundamentally on mesoscale factors, local and micro-scale factors, such as the different characteristics of the urban structure, the topography and surface of the roofs, the vegetation, as well as the anthropogenic heat generated by urban metabolism, among other factors, can modify the regional climate to the urban scale (Oke, 1973, 1987). There are significant differences in the climate of urban areas compared to those of a rural nature. The urban heat island effect (UHI) describes the influence of urban surfaces on the temperature patterns of urban areas as opposed to surrounding areas. Artificial materials (especially asphalt and concrete) usually used in urbanized areas are one of the main causes. The UHI depends on various factors, such as the degree of waterproofing of the land, the ground cover, the vegetation, the Sky View Factor or the albedo, among others (Arellano \& Roca, 2019a), such as latitude, altitude, topography or the size of the city.

The study of urban heat island (UHI) is of great importance in the context of climate change (CC). The urban climate literature has highlighted the remarkable prominence of nighttime UHI phenomenon. During nighttime the UHI effects become more evident due to the greater thermal inertia of the materials used in urban fabric. It is during the night when the heat accumulated in urban materials, especially in contexts of heat waves, can generate significant health risks. The low cooling capacity of urban construction materials negatively affects the comfort and the health of urban dwellers. The human organism and the atmosphere are in a constantly interacting physical and chemical equilibrium. All human beings are forced to react to atmospheric elements in order to guarantee the correct and optimum functioning of their organs. The urban thermal environment has a determining effect on human health and the comfort, playing an important role with regard to public health (Parsons 2014). In cases of high nighttime temperatures, as a consequence of high daytime temperatures, heat stress persists and is aggravated by the fact that the human body cannot rest at night. The most common impact of hot nights on human health is sleep and rest. Heat, along with other factors, can cause sleep disturbances and deprivation due to the necessary thermoregulation processes (Royé, 2017). In this sense, and within the context of climate change, in Mediterranean towns there is a noteworthy increase in the number of tropical nights (minimum temperature $\geq 20{ }^{\circ} \mathrm{C}$ ), and even of torrid nights (minimum temperature $\geq 25^{\circ} \mathrm{C}$ ) (Martin-Vide \& MorenoGarcía, 2020).

Traditional methods for obtaining nocturnal UHI have been directed either to extrapolation of data from weather stations (Martin-Vide \& Moreno-García, 2020), or obtaining air temperatures through urban transects (AMB, 2015, figure 1). In the first case, the lack of weather stations in urban landscapes makes it extremely difficult to obtain data to extrapolate and propose models at a detailed resolution scale. In the second case, there is a manifest difficulty in obtaining data simultaneously and significantly representative of urban and rural zones.

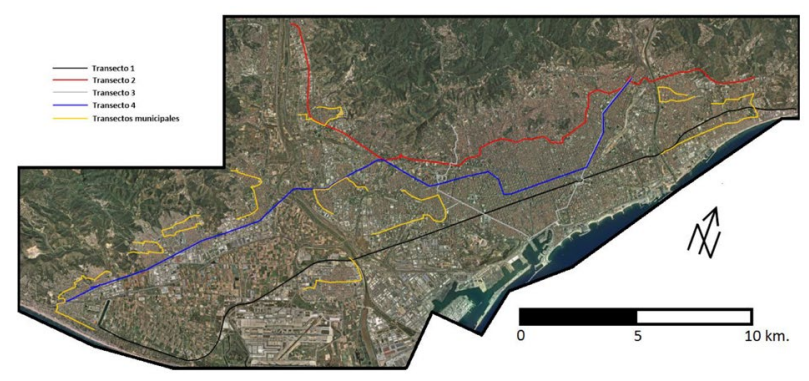

Figure 1. Urban Transects in Barcelona (AMB, 2015)

\footnotetext{
* Corresponding author
} 
The low spatial resolution of the air temperature information contrasts with the higher resolution of the thermal data of the land covers supplied by the satellite sensors. There is a high consensus that the temperature of the earth's surface (LST) plays a fundamental role in the generation of UHI, representing a determinant of surface radiation and energy exchange, as well as the control of the heat distribution between surface and atmosphere. The earth's surface temperature (LST) is a key variable that helps regulate radiation flows and heat exchanges, latent and sensitive. Therefore, modeling and prediction of environmental changes is necessary, as well as the analysis and understanding of the dynamics of LST and its relationship with changes of anthropogenic origin. The LST serves as an important indicator of the chemical, physical and biological processes of the ecosystem and is influenced, together with the latitude and type of climate, by geographic variables, such as elevation, orientation and slope, among many other factors that condition the incidence of solar radiation on the earth's surface, together with the properties of the roofs and land uses, such as color, surface roughness, humidity, chemical composition, etc. The temperature of the earth's surface regulates the lower layers of the atmosphere. Therefore, it can be identified as a key climatic variable as well as a critical factor for the urban environment since the LST modulates the energy balance.

As indicated, the composition of the land covers is one of the main factors that influence the LST, in particular the percentage of each type of land cover within the urbanized area. The constructed area can have an especially high impact. The temperature of the earth's surface has, in general, a positive correlation with the impermeable surface of urban character and negative with that occupied by forests and areas with vegetation. The decrease in vegetation influences heat balances, which leads to an increase in LST, while precipitation and evapotranspiration have the opposite tendency. The relationship between LST and green roofs and the Normalized Difference Vegetation Index (NDVI) is especially well documented in the specialized literature. The NDVI, together with other indicators of vegetation, has been widely used as an indicator of the quantity, quality and development of vegetation, as well as its impact on urbanization. The papers that have analyzed the NDVI-LST relationship show, in general, a negative correlation between both variables (Weng et al., 2004). Similarly, the existence of a positive relationship between impervious surfaces and the LST has been demonstrated.

The technologies linked to Remote Sensing have made possible the generalized study of the LST and, consequently, of the UHI at local and regional levels. The sensors installed in the satellites are characterized by a very diverse variety of spatial and temporal resolutions, generally resulting in a higher spatial resolution, a lower temporal resolution, and vice versa. Among the most used are MODIS and Sentinel3 (which offer the thermal band both day and night), with a spatial resolution of 1 $\mathrm{km} /$ pixel, and Landsat8, with $30 \mathrm{~m} /$ pixel (100 in the thermal band, only during daytime).

However, the study of the nocturnal LST is still poorly developed due to structural problems related to the availability of detailed data on the LST at night (Arellano \& Roca, 2019b). Most of the satellite sensors (Landsat, Aster, ...) allow to obtain daytime thermal images, but in a much more limited way nighttime thermal data. Only MODIS or Sentinel 3 provide abundant thermal night images, but the low resolution of these images $(1 \mathrm{~km} /$ pixel $)$ does not allow the construction of detailed models of the nocturnal UHI. For these reasons, estimating the nocturnal UHI remains a pending challenge.

This paper aims to determine nighttime LST contrasting Landsat's very limited nighttime images with daytime ones. However, the estimation of the nighttime land surface temperature by means of the Landsat thermal bands, is not a trivial question. The most used methodology to determine daytime LST is based on estimating the emissivity of the land from its degree of vegetation (NDVI threshold, Sobrino et alt., 2008). But this method shows significant limitations at night. The NDVI overvalues vegetation when considering the canopy of trees. This overestimation does not represent a serious problem during the day, when the shade of the trees limits the radiation incident on the ground. But it is critical at night. At night, the result of the application of the standard method for determining emissivity implies the underestimation of land surface radiation in areas with abundant tree vegetation. The result is critical on the streets as well as in parks with a significant degree of canopy. For this reason, this paper seeks to develop a new methodology to estimate the degree of vegetation and soil moisture, and, based on it, determine the emissivity and, consequently, the nocturnal LST.

And, once the nighttime LST is obtained, the comparison with the daytime LST allows the construction of a set of nocturnal cooling models, which, potentially, can be extrapolated to other similar climatic situations. And these models, in turn, be applied at more detailed scales $(10 \mathrm{~m} / \mathrm{pixel})$ by fusing data Landsat 8 and Sentinel 2 (Wang et alt., 2017). Downscaling data, which can help to visualize nighttime UHI more clearly

The example developed refers to heat wave situations during the summer. The case study is the Metropolitan Area of Barcelona (MAB, 35 municipalities, $636 \mathrm{~km}^{2}, 3.3$ million inhabitants, figure 2).

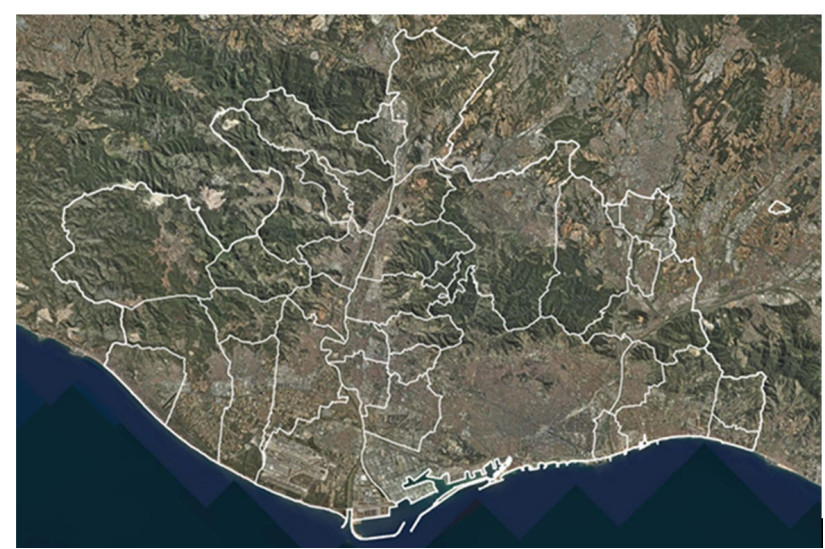

Figure 2. Metropolitan Area of Barcelona (with municipalities)

\section{METHODOLOGY}

The main methodological contributions of this paper can be synthesized as follows:

1. Propose a new methodology to estimate land covers emissivity which allows obtaining the summer night LST with a higher degree of efficiency. For this, instead of using summer NDVI, winter NDVI will be used, as it better represents the degree of vegetation at the ground level (figure 3). Winter NDVI more faithfully reproduces 
vegetation at ground level. The tree canopy plays a smaller role due to the deciduous nature of the trees in the study area. At night, when solar radiation is non-existent, longwave radiation from the ground is not significantly affected by the tree canopy. Nighttime LST resulting from the emissivity obtained by the winter NDVI clearly identifies the accumulated heat on existing street surfaces (and also, partially, in parks), such as asphalt or concrete, without being affected by the tree canopy. So, the hypothesis from which this paper is based is that the summer NDVI is not fully adequate to identify the real vegetation at ground level, which is why the winter NDVI is used as a better approximation.
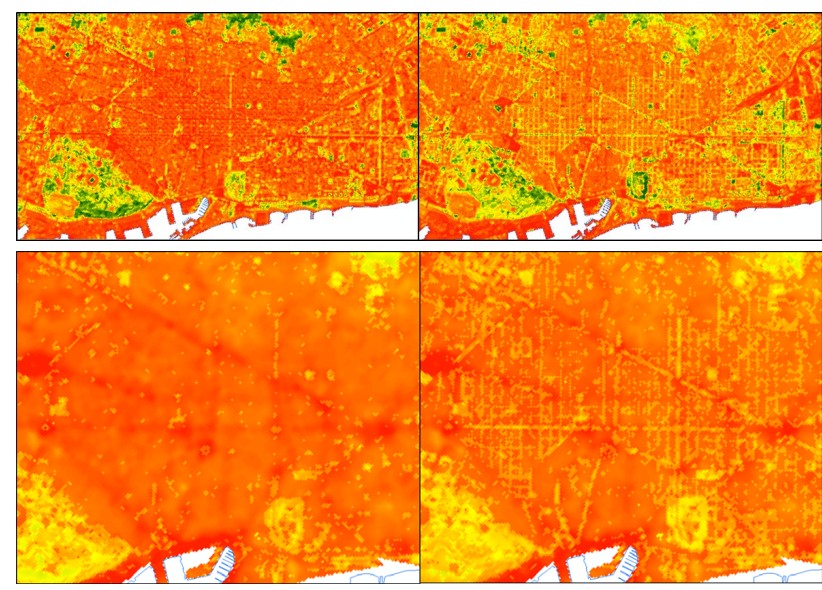

Figure 3. NDVI (winter/summer) 2015

2. The standard method to obtain the emissivity (and therefore the LST) from remote sensing images (Sobrino et al., 2008) produces a significant discontinuity due to the "cavity term" (figure 4). For this reason, various methodologies have been checked to obtain emissivity (continuous, logistic, ...), finally using the method suggested by Guo et alt. (2020).

$$
\varepsilon_{p}=\left\{\begin{array}{cl}
\varepsilon_{s} & N D V I<N D V I_{s}(\text { barren soil }) \\
\varepsilon_{v} f+\varepsilon_{s}(1-f)+4<d \varepsilon>f(1-f), & N D V I_{s} \leq N D V I \leq N D V I_{v}(\text { partly vegetated }) \\
\varepsilon_{v} & N D V I>N D V I_{s}(\text { fully vegetated })
\end{array}\right.
$$

where $\varepsilon_{p}$ is the pixel emissivity, $\varepsilon_{s}$ is the soil component emissivity, $\varepsilon_{v}$ is the vegetated component emissivity, $\langle d \varepsilon>$ is the maximum cavity term and is set as 0.01 , and $f$ is the fraction of vegetation cover (FVC). NDVIS is the NDVI for barren soil $(0.20)$; NDVIV is the NDVI for fully vegetated $(0.5)$.

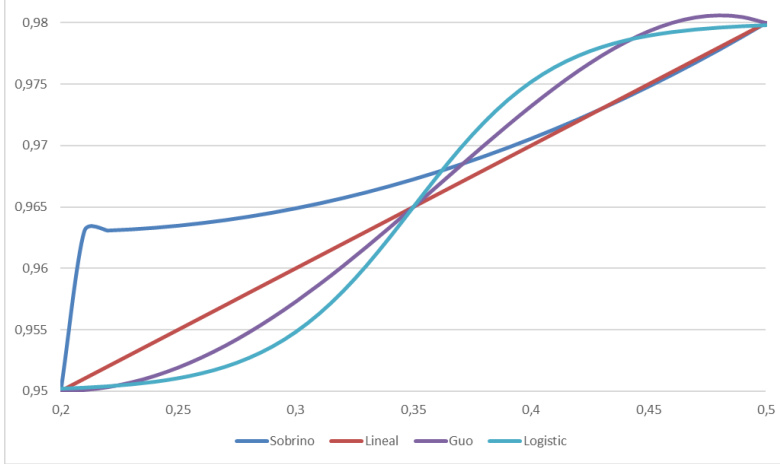

Figure 4. Emissivity vs. NDVI
3. Estimate nighttime LST using the emissivity obtained in the previous steps and compare the results with the LST obtained by means of the standard methodology (based on the summer NDVI). These results are contrasted for impervious areas where there is abundant deciduous tree vegetation. And they will also be contrasted with images of the night LST (in summer) of the Barcelona area obtained by airborne sensors with high spatial resolution.

4. Once the nighttime LST is obtained, the comparison with the daytime LST allows the construction of a set of nocturnal cooling models, which, potentially, can be extrapolated to other similar climatic situations (Arellano \& Roca, 2020). These models of night "cooling" (contrasting the day and night images of the LST) are obtained by means of multiple regression analysis, using as explanatory variables, in addition to the physical characteristics of the territory (longitude, latitude, altitude, distance to the sea, slope, orientation), the characteristics derived from artificialization (NDVI, NDBI, imperviousness, albedo, land covers, land use derived from urban planning).

\section{RESULTS}

In order to proceed with the analysis of the day and night LST, the Landsat 8 images relative to the month of August 2015 have been used $(8 / 3,8 / 28)$. In order to obtain a completely cloud-free image of the study area, the night thermal images of $8 / 28$ and 9/13 were combined (figure 5).

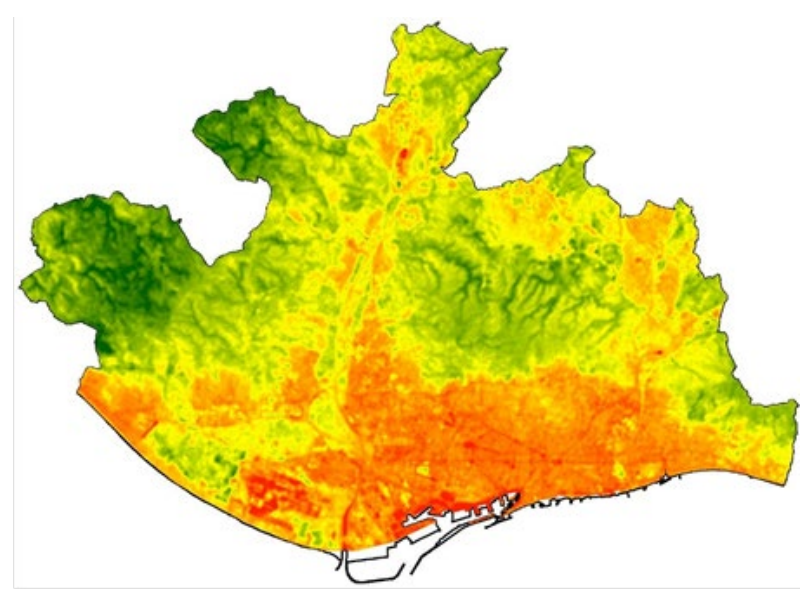

Figure 5. Band 10 (thermal). Nighttime August 2015

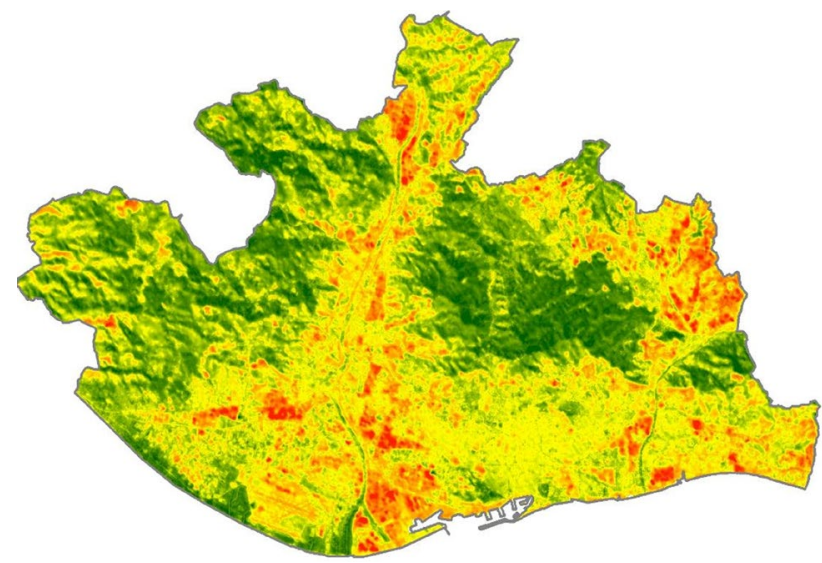

Figure 6. Daytime LST. August 2015 
Daytime LST (figure 6) was obtained by the traditional method (Sobrino et alt. 2008) based on the NDVI of the date of obtaining the Landsat images (summer NDVI). As can be seen, the daytime UHI of the MBA is not very accentuated. Although the forest areas (Collserola Park) are clearly cooler than the urbanized areas, and that the industrial land highlights for its high temperatures, the urban center of Barcelona is not particularly hot, due to the cooling resulting from the proximity to the sea. The UHI reaches 3.4 degrees, reaching the LST of the urbanized area 36.76 compared to 33.36 of the rural area.

Figure 7 shows the result of obtaining the nocturnal LST for the month of August by means of the traditional method, based on the summer NDVI. As can be seen, the UHI of the MAB appears with great clarity. Despite the greater clarity of the spatial distribution of the UHI, the LST gradient between the urbanized and rural areas is reduced to 2.59 degrees Celsius.

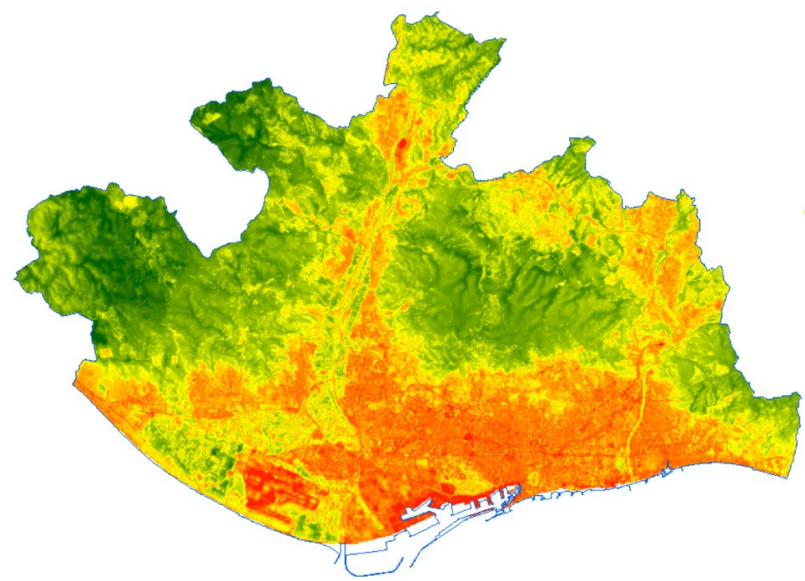

Figure 7. Nighttime LST (using summer NDVI) August 2015

For its part, figure 8 shows the result of obtaining nighttime LST of the MAB by calculating the emissivity developed by Guo et alt (2020) as well as by means of the degree of vegetation obtained by the winter NDVI. The sharpness of the nocturnal UHI is even more pronounced, since urban covers tend to have less cooling than in the standard method (passing the mean LST from $23.89^{\circ}$ to $24.10^{\circ}$ ), unlike rural covers that cool to a greater extent (from $21.30^{\circ}$ to $21.23^{\circ}$ ).

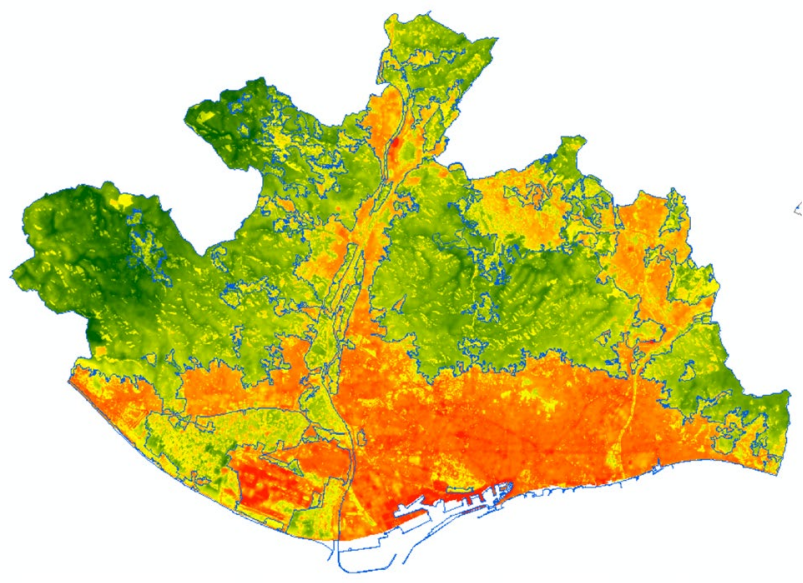

Figure 8. Nighttime LST (using winter NDVI) summer 2015 (blue line shows artificialized land)

Table n. 1 shows the Pearson correlations between the day and night LSTs with the geographic and urban variables. Night LST has a greater correlation with winter NDVI $(\mathrm{R}=-0.860)$, in contrast to the day LST, which maintains a higher correlation with summer NDVI $(\mathrm{R}=-0.750)$. Regarding the geographical variables, both longitude (+) and altitude-DTM (-) have a higher correlation with the nighttime LST than with the daytime LST. Both latitude and distance to the sea invert the sign between the day LST (+) and the night LST (-). Greater presence of water confirms a greater cooling capacity during the day $(-0.539)$ than at night $(-0.351)$. In the opposite direction, greater soil waterproofing (impervious) shows a greater correlation with the LST at night (0.748) than during the day (0.467)

\begin{tabular}{|llr|r|}
\hline & & LST_night_2015 & LST_day_2015 \\
\hline NDVI_L8_20150201 & Pearson &,- 860 &,- 554 \\
\hline NDVI_20150803 & Pearson &,- 772 &,- 750 \\
\hline long & Pearson &, 511 &, 193 \\
\hline Lat & Pearson &,- 024 &, 177 \\
\hline Dist_coast & Pearson &,- 381 &, 070 \\
\hline Water & Pearson &, 351 &, 539 \\
\hline NDBI & Pearson &, 572 &, 737 \\
\hline ALBEDO & Pearson &, 613 &, 667 \\
\hline IMPERVIOUS & Pearson &, 748 &, 467 \\
\hline DTM & Pearson &,- 701 &,- 498 \\
\hline Orientation & Pearson &,- 039 &,- 064 \\
\hline Slope & Pearson &,- 553 &,- 558 \\
\hline CLC18 & Pearson &, 833 &, 768 \\
\hline Planning & Pearson &, 736 &, 564 \\
\hline
\end{tabular}

Table 1. LST vs. NDVI

\section{1- Daytime Urban Heat Island}

The development of the OLS models allows us to approach the exercise of changing the native Landsat 100 meter / pixel scale to a real scale of 30 meters. These models can serve to understand the factors that determine the spatial distribution of the LST, as well as to visualize the UHI more clearly.

The hybrid model (table 2, figure 9) raises the explanatory power to $82.2 \%$ of the spatial variation of the daytime LST, with longitude, altitude, NDVI, impervious, orientation and slope (-), latitude, NDBI and albedo (+), and urban planning as land covers (CLC18) as variables statistically significant. The "wrong" sign for albedo and impervious is due to their high collinearity with the NDVI.

\begin{tabular}{|c|c|c|c|c|c|c|c|c|}
\hline \multirow[b]{3}{*}{ Model } & \multirow{3}{*}{$\begin{array}{l}\text { Model } \\
1 \\
\end{array}$} & \multirow{2}{*}{$\begin{array}{l}\text { R } \\
, 907\end{array}$} & square & \multicolumn{2}{|c|}{ Adjusted R2 } & \multicolumn{2}{|c|}{ Stardard error } & \multirow[b]{3}{*}{ Sig. } \\
\hline & & & 822 & & 822 & \multicolumn{2}{|c|}{1,420840741} & \\
\hline & & B & Desv & v. Error & & eta & $\mathrm{t}$ & \\
\hline \multirow[t]{15}{*}{1} & (Constant) & $-464,217$ & & 3,945 & & & $-117,673$ & .000 \\
\hline & NDVI_20150803 & $-5,451$ & & ,031 & & -.266 & $-173,467$ & ,000 \\
\hline & Iong & $-8,211 \mathrm{E}-5$ & &, 000 & &,- 200 & $-92,868$ &, 000 \\
\hline & Latitud &, 000 & & .000 & & ,251 & 119,866 & .000 \\
\hline & Dist_coast & $6,463 \mathrm{E}-5$ & &, 000 & & .110 & 53,349 & ,000 \\
\hline & Water &, 905 & & .022 & & .036 & 41,444 &, 000 \\
\hline & Artificial &,- 437 & & .005 & &,- 065 & $-81,327$ & .000 \\
\hline & NDBI & 6,596 & & .039 & &, 252 & 169,119 & .000 \\
\hline & ALBEDO & 10,175 & & .087 & & .098 & 116,958 & .000 \\
\hline & IMPERM &,- 009 & &, 000 & &,- 092 & $-108,407$ & .000 \\
\hline & DTM_MAB &,- 003 & & .000 & &,- 126 & $-140,626$ & .000 \\
\hline & Orientation_MAB & .000 & & .000 & &,- 009 & $-17,980$ & .000 \\
\hline & Slope_MAB &,- 035 & & .000 & &,- 100 & $-140,726$ & .000 \\
\hline & CLC18 & .461 & & .001 & & 353 & 406,761 & .000 \\
\hline & Planning & .076 & & 001 & & .043 & 57,689 & .000 \\
\hline
\end{tabular}

Table 2. Daytime LST hybrid model 
In the hybrid model, CLC 2018 reaches a higher explanatory level of the spatial variation of the LST $(t=406.761)$. Nonirrigated arable land $\left(39.94^{\circ}\right)$, industrial and commercial units $\left(38.99^{\circ}\right)$, roads and rail networks $\left(38.34^{\circ}\right)$ and airports $\left(37.48^{\circ}\right)$ are the hottest covers. On the other hand, coastal lagoons and estuaries $\left(30.26^{\circ}\right)$, broad-leaved forest $\left(30.36^{\circ}\right)$, mixed forest $\left(31.47^{\circ}\right)$, and coniferous forest $\left(31.62^{\circ}\right)$ are the coolest covers. Continuous urban fabric $\left(36.05^{\circ}\right)$ reaches a temperature higher than the average for the entire MAB $\left(34.96^{\circ}\right)$, slightly above discontinuous urban fabric $\left(35.73^{\circ}\right)$. Single family homes $\left(35.15^{\circ}\right)$, reach a temperature slightly cooler than historic centers $\left(35.97^{\circ}\right)$ and compact residential areas $\left(36.12^{\circ}\right)$.

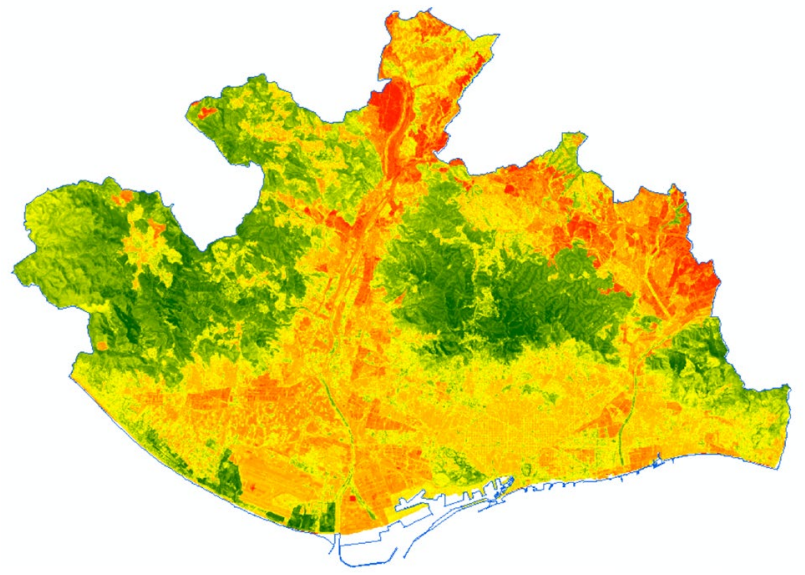

Figure 9. Daytime LST (hybrid model)

The segmented model (table 3, figure 10) by land artificialization (rural vs. urban) obtains an $\mathrm{R}^{2}$ of 0.839 . In rural land, the most significant variables are Corine Land Covers $(+)$, altitude (-), latitude, water and NDBI (+), and NDVI and slope $(-)$. In urban land stand out CLC (+), NDVI and slope (-), distance to the coast and NDBI $(+)$ and impervious $(-)$. As in the hybrid model, the "wrong" sign for albedo and impervious is due to their high collinearity with the NDVI.

\begin{tabular}{|c|c|c|c|c|c|c|c|}
\hline \multirow[b]{3}{*}{ Artificial } & Model & $\mathrm{R}$ & $\mathrm{R}$ square & Adjusted R2 & \multicolumn{2}{|c|}{$\begin{array}{l}\text { Standard } \\
\text { error }\end{array}$} & \multirow[b]{3}{*}{ Sig. } \\
\hline & 1 & 916 & 839 & 839 & \multicolumn{2}{|c|}{1,353067608} & \\
\hline & Model & & $B$ & Desv. Error & Beta & $t$ & \\
\hline \multirow[t]{14}{*}{ Rural } & & (Constant term) & $-635,765$ & 5,440 & & $-116,861$ & .000 \\
\hline & & NDV__20150803 & $-5,018$ & .043 & -196 & $-117,682$ & .000 \\
\hline & & long & .000 & .000 & -.276 & $-97,551$ & .000 \\
\hline & & Latitud & .000 & .000 & 369 & 119,629 & .000 \\
\hline & & Dist_coast & $-6,852 \mathrm{E}-6$ & .000 & -.011 & $-4,217$ & .000 \\
\hline & & Water & 4,033 & .034 & 163 & 119,126 & .000 \\
\hline & & NDBI & 6,520 & .055 & 246 & 118,049 & .000 \\
\hline & & ALBEDO & 12,870 & .173 & .098 & 74,278 & .000 \\
\hline & & Impervious & -.001 & .000 & -.002 & $-2,227$ & .026 \\
\hline & & DTM_MAB & -.004 & .000 &,- 187 & $-163,531$ & .000 \\
\hline & & Orientation_MAB &,- 001 & .000 & -.018 & $-25,491$ & .000 \\
\hline & & Slope_MAB &,- 029 & , 000 &,- 087 & $-101,269$ & .000 \\
\hline & & CLC18 & 320 & .001 & .227 & 224,428 & .000 \\
\hline & & Planning & .003 & .002 & .001 & 1,610 & 107 \\
\hline \multirow[t]{14}{*}{ Urban } & & (Constant term) & $-155,328$ & 5,828 & & $-26,653$ & .000 \\
\hline & & NDVI_20150803 & $-5,839$ & ,044 & -309 & $-131,295$ & .000 \\
\hline & & long & $-6,458 \mathrm{E}-6$ &, 000 & -019 & $-4,368$ & .000 \\
\hline & & Latitud & $3,755 \mathrm{E}-5$ & .000 & 111 & 26,753 & .000 \\
\hline & & Dist_coast &, 000 &, 000 & 454 & 96,656 &, 000 \\
\hline & & Water & $-1,112$ &, 029 & -.053 & $-38,221$ & .000 \\
\hline & & NDBI & 4,590 &, 052 & 185 & 88,774 & .000 \\
\hline & & ALBEDO & 4,666 & ,097 & 059 & 47,987 & ,000 \\
\hline & & Impervious &,- 006 &, 000 &,- 093 & $-62,787$ &, 000 \\
\hline & & DTM_MAB &,- 002 &, 000 &,- 062 & $-44,060$ & .000 \\
\hline & & Orientation_MAB & $-2,864 E-5$ & , 000 & -001 & $-1,094$ & .274 \\
\hline & & Slope_MAB & - 054 & ,000 & -144 & $-126,161$ & .000 \\
\hline & & CLC18 & 516 & ,002 & 322 & 266,663 & ,000 \\
\hline & & Planning & .112 & .002 & 082 & 68,540 & .000 \\
\hline
\end{tabular}

Table 3. Daytime LST segmented model

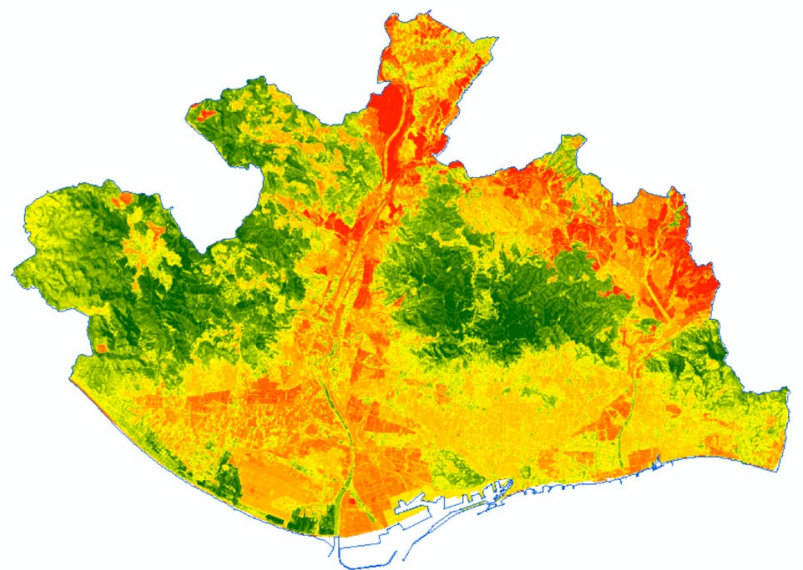

Figure 10. Daytime LST (segmented model)

\section{2- Nighttime Urban Heat Island}

The construction of the hybrid OLS model of nighttime LST (table 4, figure 11), allows to explain $88.9 \%$ of the spatial distribution of LST at night, with NDVI (-) as main explanatory variable. Next, the geographical variables stand out: altitude (-), longitude $(+)$, latitude $(-)$, distance to the coast $(+)$ and slope $(+)$ The rest of the variables are also significant and appear with the correct sign, highlighting impervious $(+)$.

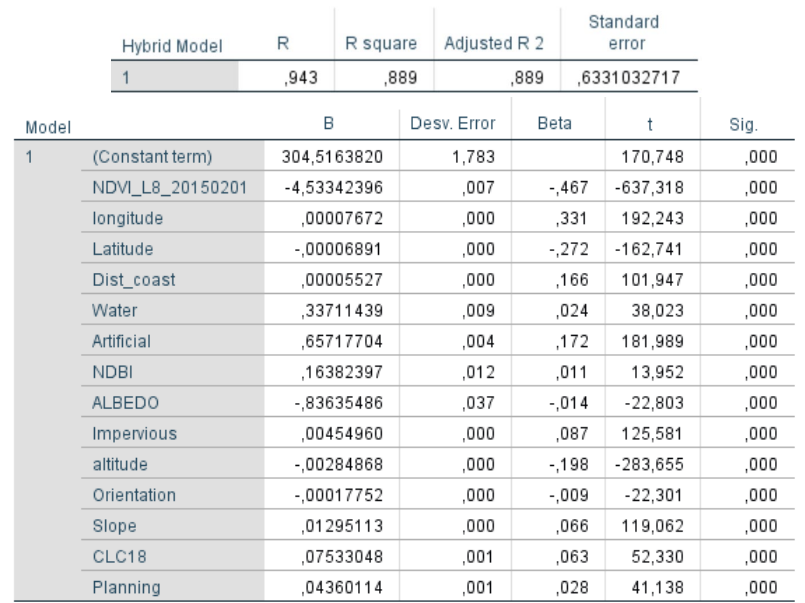

Table 4. Nighttime LST hybrid model

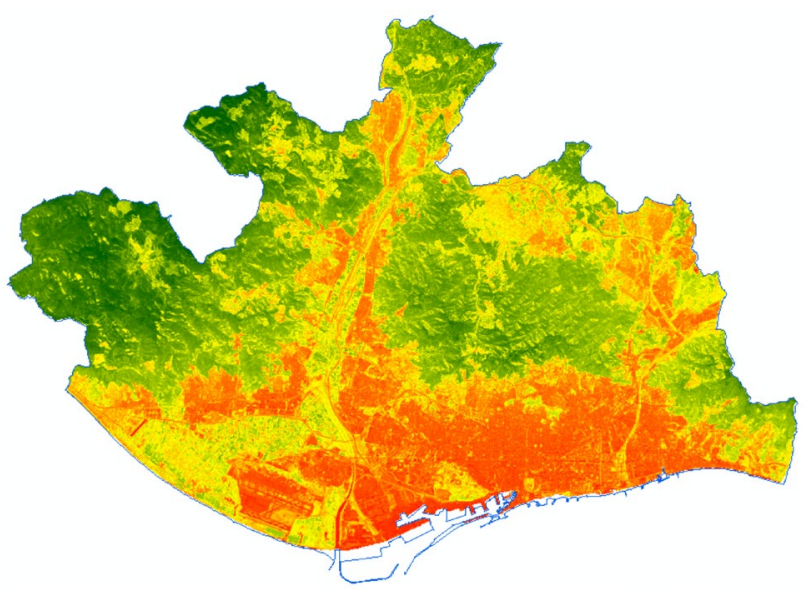

Figure 11. Nighttime LST (hybrid model) 
During the night the port $\left(26.09^{\circ}\right)$, airport $\left(25.07^{\circ}\right)$, continuous urban fabric $\left(24.95^{\circ}\right)$, the land closest to the sea $\left(24.76^{\circ}\right)$ and the industrial areas $\left(24.31^{\circ}\right)$ are the hottest covers. In contrast, mixed forestry $\left(20.14^{\circ}\right)$, dump sites $\left(20.30^{\circ}\right)$, inland marshes $\left(20.58^{\circ}\right)$, land with abundant vegetation $\left(20.78^{\circ}\right)$ and broadlived forest $\left(20.98^{\circ}\right)$ are the coolest covers. Discontinuous urban fabric area $\left(23.36^{\circ}\right)$ is about 1.5 degrees cooler than the compact city, although higher than the average temperature of the MAB $\left(22.57^{\circ}\right)$. Single-family homes $\left(22.52^{\circ}\right)$, reach a temperature slightly lower than the metropolitan average, and are more than $2.5^{\circ}$ cooler than the compact central city $\left(25.05^{\circ}\right)$, historical centers $\left(24.90^{\circ}\right)$, and even residential areas of medium density and open buildings $\left(24.47^{\circ}\right)$.

The segmented model by land artificialization (rural vs. urban) obtains an $\mathrm{R}^{2}$ of 0.899 (table 5, figure 12), with all significant variables, among which stand out NDVI $(-)$, both in rural and urban land. Altitude (-), longitude (+), slope (+) and latitude (-) in rural land. And altitude (-), longitude $(+)$ and latitude (-) in urban land. The "wrong" sign of NDBI in urban land cover is due to their high collinearity with the NDVI.

\begin{tabular}{|c|c|c|c|c|c|c|}
\hline \multirow[b]{3}{*}{ Artificial } & Segmented Model & R square & Adjusted R2 & \multicolumn{2}{|c|}{ Standar error } & \multirow[b]{3}{*}{ sig. } \\
\hline & 1 & .948 & 89 & .603 & 798364 & \\
\hline & Segmented Model & B & Desv. Error & Beta & $\mathrm{t}$ & \\
\hline \multirow[t]{14}{*}{ Rural } & (Constant) & 389,5111910 & 2,278 & & 171,020 & .000 \\
\hline & NDV_L8_2015020 & $-3,85688798$ & .008 & -481 & $-467,888$ & .000 \\
\hline & Iongitude & .00009242 & .000 & .663 & 195,048 & .000 \\
\hline & Latitude & -00008956 & .000 & -.614 & $-166,812$ & .000 \\
\hline & Dist_coast & .00009907 & .000 & .473 & 148,123 & .000 \\
\hline & Water &,- 03490336 & .013 &,- 004 & $-2,750$ & .006 \\
\hline & NDBI & .57059778 & .015 & .062 & 38,926 & .000 \\
\hline & ALBEDO & 4,64563846 & .072 & .101 & 64,721 & .000 \\
\hline & Impervious &, 01131545 & .000 & .084 & 97,100 & .000 \\
\hline & Altitude &,- 00227513 & .000 &,- 281 & $-207,752$ &, 000 \\
\hline & Orientation_MAB & .00004238 & .000 & .004 & 4,482 & .000 \\
\hline & Slope_MAB & .02216154 & .000 & .191 & 185,200 & .000 \\
\hline & CLC18 & .06748914 & .002 & .038 & 31,940 & .000 \\
\hline & Planning & .11616939 & .002 & .072 & 74,336 & .000 \\
\hline \multirow[t]{14}{*}{ Urban } & (Constant) & 261,4911476 & 2,816 & & 92,864 & .000 \\
\hline & NDV_L8_2015020 & $-5,36792521$ & .013 & -595 & $-426,984$ & .000 \\
\hline & longitude & .00006721 & .000 & 347 & 93,980 & .000 \\
\hline & Latitude &,- 00005813 & .000 &,- 302 & $.85,844$ & .000 \\
\hline & Dist_coast & .00002965 & .000 & .125 & 31,421 & .000 \\
\hline & Water & .50056392 & .013 & .042 & 39,769 & .000 \\
\hline & NDBI &,- 81315729 & .019 & -058 & $-43,941$ & .000 \\
\hline & ALBEDO & $-2,54764975$ & .045 & -057 & $-56,715$ & .000 \\
\hline & Impervious & .00222787 & .000 & .062 & 47,612 & .000 \\
\hline & Altitude &,- 00369979 & .000 &,- 211 & $-177,722$ &, 000 \\
\hline & Orientation_MAB &,- 00016233 & .000 & -011 & $-12,914$ & .000 \\
\hline & Slope_MAB & -00293198 & .000 &,- 014 & $-14,352$ & .000 \\
\hline & CLC18 & .08856023 & .002 & .049 & 45,944 & .000 \\
\hline & Planning & -00575962 & .001 & -.004 & $-4,083$ & .000 \\
\hline
\end{tabular}

Table 5. Nighttime LST segmented model

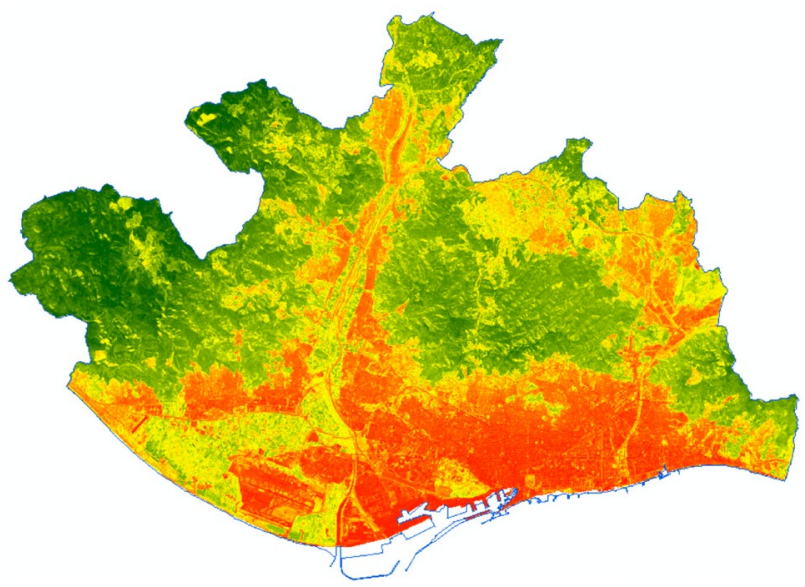

Figure 11. Nighttime LST (degmented model)

\section{DISCUSSION}

The comparison between the LST resulting from the application of the standard method (obtaining the PV with the summer NDVI and the emissivity with the PV suggested by Sobrino et al. 2008) with the one resulting from the application of the method proposed in this paper (using the Winter NDVI and emissivity with the methodology proposed by Guo et al. 2020) shows an open contradiction in the road space (figure 12).

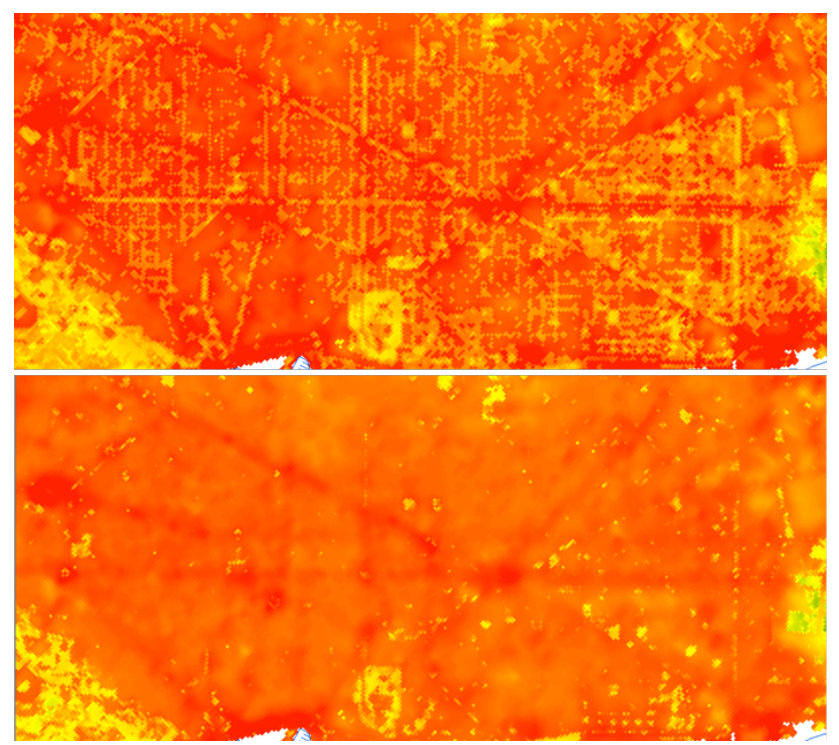

Figure 12. Standard vs. new method to obtain nighttime LST

The LST of the streets (and also, partially, of the urban parks) appears clearly cooler than the real one when the standard method is applied. The tree canopy, which during the day represents an important factor in reducing incoming solar radiation, does not have any positive factor in reducing nighttime temperatures. However, when correcting the thermal band of Landsat 8 by means of the summer NDVI (with the treetops in all their splendor) the application of the traditional method represents an excessive cooling of the street surfaces, characterized by materials (asphalt and concrete) that accumulate a lot of heat throughout the hours of solar radiation.

In order to contrast the hypothesis that the winter NDVI represents a better alternative to determine the land emissivity and, consequently, the LST, the results of applying the standard and the new methodology have been compared in relation to an image provided by Institut Cartogràfic i Geològic de Catalunya (ICGC, https://www.icgc.cat/en/). This is the LST was obtained by a flight carried out on September 26, 2014, and despite being from a previous year, it accurately represents the temperature of the land covers at the end of summer, when deciduous trees existing on the streets of Barcelona have not yet lost their leaves.

The thermal images were obtained between 0:47 and 1:52 local time by an airborne TASI sensor. The spectral window covered by the TASI sensor covers the most significant part of the Thermal InfraRed (TIR) and allows the retrieval of quantitative information on the temperature of the observed cover and its chemical composition. In the case of TIR acquisitions, the temperature parameter and the emissivity spectrum are coupled when determining the amount of thermal radiation emitted by the observed cover reaching the sensor. The spectral window covered by the TASI sensor covers the most significant part of 
the Thermal InfraRed (TIR) and allows the retrieval of quantitative information on the temperature of the observed cover and its chemical composition. In the case of TIR acquisitions, the temperature parameter and the emissivity spectrum are coupled when determining the amount of thermal radiation emitted by the observed cover reaching the sensor. The quantitative recovery of the absolute temperature parameter, key for different applications, goes through an additional process of atmospheric correction (ModTRan5.0 code with simultaneous radiosounding in flight) and decoupling of the emissivity spectrum called TES (Temperature and Emissivity Separation). The TES result is an absolute temperature value and a vector of 32 emissivities for each pixel in the image. The spatial resolution is 4 meters/pixel, and the spectral resolution is 16 bits. Figure 13 shows the LST obtained in the center of Barcelona (Eixample district).

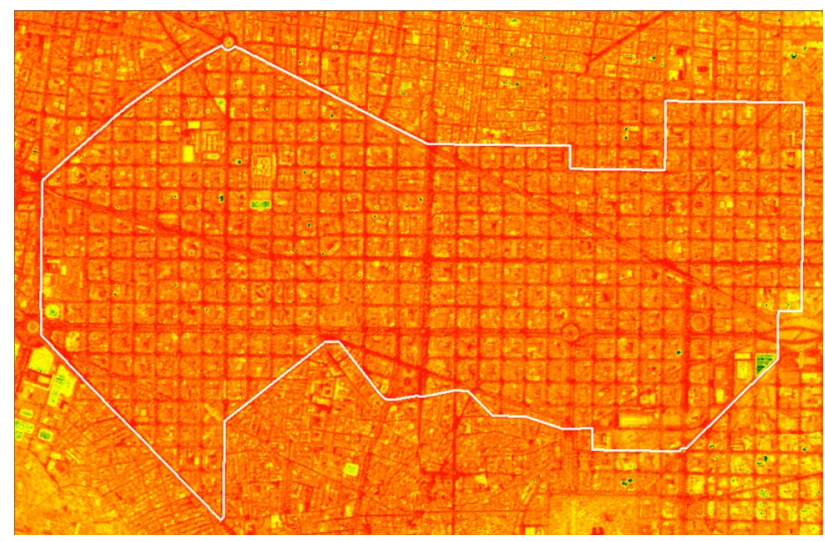

Figure 13. LST September 2014 (ICGC)

As can be seen, the LST of the ICGC is more similar to the LST obtained through the new methodology than with the standard methodology based on the summer NDVI. Despite the fact that the correlations obtained are very low, given the very different spatial resolution of the analyzed images ( 4 meters in the TASI sensor image and 100 meters in the Landsat 8 thermal band), the image obtained with the methodology proposed in this paper achieves a higher Pearson correlation (0.190) than the image obtained by the standard methodology $(-0.038)$. The negative sign of the correlation clearly shows the inadequacy of the application of the summer NDVI to obtain nocturnal LST. This inadequacy is especially evident in the case of the streets. The streets obtain, in the standard methodology, an LST $20.2 \%$ cooler than the average of the Eixample district, while in the thermal image of the ICGC they have an LST $4.7 \%$ warmer than the average. With the new methodology, the LST obtained in the streets of Eixample is $0.3 \%$ higher than the district average.

The inadequacy of obtaining the nighttime LST of tree-lined streets by means of the summer NDVI is also deduced from the information obtained in situ by means of thermal camera. Field studies carried out in Barcelona Metropolitan Area confirm that the LST of the asphalt of the roads and the concrete of the sidewalks of the streets maintain a high temperature at night, regardless of being or not under the treetops. Table n. 6 shows the temperature obtained by means of a (calibrated) thermal camera of different materials in a sample of 5 study areas in the urban continuum of Viladecans-Gavà-Castelledefels (MAB). The table shows, for daytime and nighttime field measurements, the daytime and nighttime air temperatures, as well as the land surface temperatures for asphalt, concrete, bare soil, grass and rubber, differentiating whether the materials were exposed. directly to solar radiation, in the shade or if the measurements were taken at night.

\begin{tabular}{|c|c|c|c|c|c|c|c|c|}
\hline & & $\begin{array}{l}\text { Riera S. } \\
\text { Climent }\end{array}$ & $\begin{array}{c}\text { Torrent } \\
\text { Ballester }\end{array}$ & Torre Lluch & Muntanyeta & Tallanaires & MEAN & Ratio \\
\hline \multirow{3}{*}{ Air Temp. } & Day & 33,00 & 33,43 & 31,85 & 35,42 & 34,36 & 33,61 & \\
\hline & Night & 22,26 & 25,50 & 25,11 & 27,96 & 28,33 & 25,83 & \\
\hline & Sun & 49,49 & 52,80 & 49,64 & 52,93 & 52,66 & 51,50 & \\
\hline \multirow[t]{2}{*}{ Mean Measures } & Shadow & 34,72 & 37,54 & 38,98 & 37,98 & 40,30 & 37,90 & \\
\hline & Night & 24,87 & 29,17 & 28,90 & 31,22 & 32,04 & 29,24 & \\
\hline \multirow{3}{*}{ Asphalt } & Sun & 52,81 & 55,11 & 53,09 & 56,29 & 55,11 & 54,48 & 1,06 \\
\hline & Shadow & 36,19 & 39,73 & 40,78 & 40,78 & 44,20 & 40,34 & 1,06 \\
\hline & Night & 26,94 & 30,06 & 29,41 & 33,16 & 34,05 & 30,72 & 1,05 \\
\hline \multirow{3}{*}{ Concrete } & Sun & 50,39 & 53,03 & 47,71 & 52,61 & 53,21 & 51,39 & 1,00 \\
\hline & Shadow & 34,26 & 35,76 & 37,73 & 37,44 & 39,78 & 36,99 & 0,98 \\
\hline & Night & 26,22 & 30,21 & 29,26 & 31,36 & 33,00 & 30,01 & 1,03 \\
\hline \multirow{3}{*}{ Bare Soil } & Sun & 49,81 & 52,65 & 46,67 & 54,43 & 52,88 & 51,29 & 1,00 \\
\hline & Shadow & 34,68 & 38,90 & 38,67 & 37,58 & 38,83 & 37,73 & 1,00 \\
\hline & Night & 21,51 & 25,57 & 26,80 & 28,70 & 29,7 & 26,46 & 0,90 \\
\hline \multirow{3}{*}{ Grass } & Sun & 35,67 & 38,90 & & 39,26 & 42,4 & 39,06 & 0,76 \\
\hline & Shadow & 30,40 & 31,65 & 29,70 & 30,24 & 31,18 & 30,63 & 0,81 \\
\hline & Night & 18,87 & 25,65 & 23,00 & 24,60 & 26,12 & 23,65 & 0,81 \\
\hline \multirow{3}{*}{ Rubber } & Sun & 59,30 & 70,40 & 54,10 & & & 61,27 & 1,19 \\
\hline & Shadow & 36,10 & 39,30 & 37,40 & & & 37,60 & 0,99 \\
\hline & Night & 22,25 & 25,70 & 26,60 & & & 24,85 & 0,85 \\
\hline
\end{tabular}

Table 6. LST of different materials in public space

The study was carried out in a heat wave episode, with an average air temperature of 33.61 degrees during daytime and 25.83 at night field measurements. As can be seen in the table, asphalt and concrete maintain high radiant temperatures during the night, $5 \%$ and $3 \%$ higher than the average of all measurements. The bare soil, hot during the hours of sunlight $($ ratio $=1)$, cooled significantly during the night (ratio $=0.90)$. Vegetated soil (grass) is always cooler than the average of field measurements: between $24 \%$ during the day (on surfaces exposed to the sun) and $19 \%$ at night. And rubber, very hot during the day (ratio $=1.19$ ), gets very cold at night $($ ratio $=$ $0.85)$.

The field measurements confirm the results obtained in the analysis of the image of land surface temperature from the TASI sensor: the dominant materials in the streets (asphalt and concrete) have a higher thermal inertia than the rest of the materials, which determines a higher nocturnal LST (between $3 \%$ and $5 \%$ ). Therefore, it is necessary to modify, especially in the case of night thermal images obtained at lower resolution, the standard methodology consisting of determining the summer emissivity of the land (and therefore the LST) as a function of the summer NDVI.

In the same way that it is necessary to modify the emissivity in the case of water bodies (which have a very low NDVI), it is necessary to estimate the summer emissivity of streets (and, in general, of wooded surfaces) based on the true vegetation existing at ground level. Not at tree canopy. Unfortunately, the information on the impervious soil surface provided by Copernicus (EEA, 2016) is not reliable, since it also considers the summer NDVI to estimate the impervious degree. The solution proposed in this paper (use winter NDVI to identify real vegetation at ground level) is a step in this direction. But still insufficient. Obtaining soil emissivity at night continues to be a pending challenge.

\section{CONCLUSSIONS}

The analysis carried out in this paper has highlighted the limitations of the standard methodology for obtaining the summer nighttime LST from the emissivity estimated by NDVI of the same summer season. The spring-summer NDVI overestimates the true extent of vegetation at ground level. The shadow projected on the ground by the tree canopy during the day, cool certainly land surface temperature (and air temperature). But during the night this beneficial effect 
disappears almost completely, as the impermeable soil radiates the heat accumulated during the hours of sunlight. The comparison between nighttime LST obtained by the standard methodology with the ICGC high resolution thermal image confirms that this methodology does not allow the reproduction of the summer night LST with an adequate level of precision, especially in areas characterized by deciduous trees.

It is therefore necessary to promote a profound modification of the standard methodology to estimate nocturnal emissivity. In this work, it has been proposed to replace the summer NDVI with the winter one, as the latter more adequately reflects the degree of vegetation at the ground level. Comparison of the results obtained by this approach with the ICGC image confirms a better performance. However, the knowledge of the nocturnal emissivity at the native resolution of the thermal bands of Landsat 8 continues to be a pending challenge. It is necessary to deepen the study of the nocturnal emissivity of the vegetation (when the evapotranspiration of the plants almost completely disappears), especially on warm nights with high ambient humidity. It is also necessary to know in greater detail the imperviousness of the land, a key aspect to establish the effect of humidity on the transmission of heat.

The day and night OLS models developed in this work allow us to be optimistic about the possibilities of replicating these models in other similar climatic situations, in which there are no night thermal images. The scarcity of such images at a medium / high resolution, such as that of Landsat 8 , can perhaps be compensated with the application of the cooling models developed. The combination of the MODIS and Sentinel 3 nighttime LST images, with those cooling models, opens a significant path that must be explored.

In any case, the OLS models allow a more precise and detailed visualization of the UHI during the day and at night. As well as better understanding the causes of the structure of the spatial distribution of the LST.

\section{ACKNOWLEDGEMENTS}

Thanks to the Ministry of Economy and Competitiveness of Spain (MINECO) and the European Regional Development Fund (ERDF) that financed the project Extreme Spatial and Urban Planning Tool for Episodes of Heat Waves and Flash Floods. Building resilience for cities and regions (X-ClimPlan).

Thanks, also, to the Institut Cartogràfic i Geològic de Catalunya for providing us with a detailed image of the Barcelona LST at the end of summer 2014.

\section{REFERENCES}

Área Metropolitana de Barcelona, 2015: La Isla de Calor Urbano en el Área Metropolitana de Barcelona y la adaptación al Cambio Climático. AMB, 2015.

Arellano, B. and Roca, J., 2019a: Multi-scale approach to quantify the influence of urban green spaces on urban climate. Proc. SPIE 11127, Earth Observing Systems XXIV, 111272E.

Arellano, B. and Roca, J., 2019b: Combining different sensors for the detailed analysis of the daytime and nighttime UHI.
Proc. SPIE 11157, Remote Sensing Technologies and Applications in Urban Environments IV, 1115703.

Arellano, B. and Roca, J., 2020: Urban landscapes and night time Urban Heat Island. Proc. of SPIE 11535., Remote Sensing Technologies and Applications in Urban Environments V 1153504 .

European Environment Agency (EEA), 2016: Copernicus Land Monitoring Service - High Resolution Layer Imperviousness Product Specifications.

Guo, J., Ren, H., Zheng, Y., Lu, S. and Dong, J., 2020: Evaluation of Land Surface Temperature Retrieval from Landsat 8/TIRS Images before and after Stray Light Correction Using the SURFRAD Dataset. Remote Sensing, 12, 1023.

Martin-Vide, J. \& Moreno-García, M.C., 2020: Probability values for the intensity of Barcelona's urban heat island (Spain). Atmospheric Research, vol. 240, August 2020, 104877.

Oke, T.R., 1973: City size and the urban heat island. Atmospheric Environment (1967), volume 7, Issue 8, p. 769779.

Oke, T.R., 1987: Boundary Layer Climates. Second edition. Taylor \& Francis.

Parsons, K., 2014: Human thermal environments. The effects of hot, moderate and cold environments on human health, comfort and performance. 3rd edition. CRC Press.

Royé, D., 2017: The effects of hot nights on mortality in arcelona, Spain. International Journal of Biometeorology, vol. 61, p. $2127-2140$.

Sobrino, J.A.; Jiménez-Muñoz, J.C.; Sòria, G.; Romaguera, M.; Guanter, L.; Moreno, J.; Plaza, A.; Martínez, P., 2008. Land surface emissivity retrieval from different VNIR and TIR sensors. IEEE Trans. Geosci. Remote Sens, 46, 316-327.

Wang, Q. et al., 2017. Fusion of Landsat 8 OLI and Sentinel-2 MSI Data, in IEEE Transactions on Geoscience and Remote Sensing, vol. 55, no. 7, pp. 3885-3899, July 2017.

Weng, Q., Lu, D. and Schubring, J., 2004: Estimation of land surface temperature-vegetation abundance relationship for urban heat island studies. Remote Sensing of Environment, 89 (4), 467-483. 